\title{
Электронный обмен между нейтральными и ионизованными примесными центрами железа в стеклообразном селениде мышьяка
}

\author{
(C) А.В. Марченко ${ }^{1}$, Е.И. Теруков ${ }^{2}$, А.Ю. Егорова ${ }^{3}$, В.С. Киселев ${ }^{1}$, П.П. Серегин ${ }^{1}$ \\ ${ }^{1}$ Российский государственный педагогический университет им. А.И. Герцена, \\ 191186 Санкт-Петербург, Россия \\ ${ }^{2}$ Физико-технический институт им. А.Ф.Иоффре Российской академии наук, \\ 194021 Санкт-Петербург, Россия \\ ${ }^{3}$ Санкт-Петербургский горный университет, \\ 199106 Санкт-Петербург, Россия \\ E-mail: ppseregin@mail.ru
}

(Получена 22 сентября 2016 г. Принята к печати 3 октября 2016 г.)

\begin{abstract}
Примесные атомы железа в стеклообразных пленках селенида мышьяка $\mathrm{As}_{2} \mathrm{Se}_{3}$, модифицированных железом, образуют одноэлектронные донорные центры с энергией ионизации 0.24(3) эВ (энергия отсчитывается от дна зоны проводимости). Уровень Ферми с ростом концентрации железа смещается от середины запрещенной зоны к положению донорного уровня железа за счет заполнения одноэлектронных состояний акцепторного типа, лежащих ниже уровня Ферми. При концентрациях железа $\geq 3$ ат\% с увеличением температуры выше $350 \mathrm{~K}$ наблюдается процесс электронного обмена между нейтральными и ионизованными центрами железа, приводящий к изменению как электронной плотности, так и тензора градиента электрического поля на ядрах атомов железа.
\end{abstract}

DOI: 10.21883/FTP.2017.04.44338.8411

\section{1. Введение}

Мессбауэровская спектроскопия является эффективным методом идентификации примесных атомов в кристаллических и аморфных полупроводниках - параметры мессбауэровских спектров позволяют определять зарядовое состояние примеси, симметрию и химическую природу ее локального окружения, параметры процессов электронного обмена между нейтральными и ионизованными состояниями примесного центра [1]. По-видимому, впервые методом мессбауэровской спектроскопии процесс электронного обмена между одноэлектронными примесными центрами наблюдался авторами [2] на примере примесных атомов железа в полупроводниковых соединениях $\mathrm{GaAs}$ и $\mathrm{GaP}$, тогда как аналогичный процесс электронного обмена между двухэлектронными центрами был исследован на примере примесных атомов олова в халькогенидах свинца [3]. В настоящей работе приводятся результаты по обнаружению процесса электронного обмена между нейтральными и ионизованными состояниями примесных атомов железа в пленках стеклообразного селенида мышьяка $\mathrm{As}_{2} \mathrm{Se}_{3}$, модифицированных железом.

\section{2. Методика эксперимента}

Модифицирование пленок $\mathrm{As}_{2} \mathrm{Se}_{3}$ железом проводилось путем высокочастотного ионно-плазменного распыления селенида мышьяка и металлического железа (обогащенного изотопом ${ }^{57} \mathrm{Fe}$ до 92\%) в атмосфере аргона при давлении $10^{-2}$ Торр на частоте $13.6 \mathrm{MГц} \mathrm{с}$ последующим отжигом пленок при $150^{\circ} \mathrm{C}$ в течение 30 мин. Концентрация железа $\left(N_{\mathrm{Fe}}\right)$ менялась от 0.5 до 4.0 ат\%, и при этом она контролировалась методом рентгенофлуоресцентного анализа с погрешностью \pm 0.1 ат\% [4], тогда как аморфность пленок проверялась методом рентгенофазового анализа. Мессбауэровские спектры ${ }^{57} \mathrm{Fe}$ снимались в интервале температур от 80 до $400 \mathrm{~K}$ с источником ${ }^{57} \mathrm{Co}$ в палладии. Температурная зависимость электропроводности и знак термоэдс измерялись по стандартным методикам. Погрешность в определении энергии активации электропроводности $E_{\sigma}$ составляла \pm 0.05 эВ. Положение края оптического поглощения чистых и легированных стекол $\mathrm{As}_{2} \mathrm{Se}_{3}$ определялось в интервале 600-2500 мкм при $20^{\circ} \mathrm{C}$, погрешность определения положения края оптического поглощения была не хуже \pm 0.02 эВ.

\section{3. Экспериментальные результаты и их обсуждение}

Согласно коэффициенту термоэдс, пленки $\mathrm{As}_{2} \mathrm{Se}_{3}$, не содержащие железа, обладали дырочным характером проводимости, тогда как модифицирование пленок железом уже при концентрации $N_{\mathrm{Fe}}=0.5$ ат\% приводило к электронному типу проводимости. Введение железа приводит к увеличению проводимости и уменьшению энергии активации проводимости $E_{\sigma}$ (при этом $E_{\sigma}$ стремится к предельному значению 0.24 эВ при $N_{\mathrm{Fe}}=4 \mathrm{aT} \%$ ) (рис. 1). Оптическая ширина запрещенной зоны пленок $E_{\text {opt }}$ также уменьшается с ростом концентрации железа, но не столь катастрофично, как уменьшается $E_{\sigma}$ (рис. 1 ).

Мессбауэровские спектры примесных атомов ${ }^{57} \mathrm{Fe}$ в модифицированных пленках $\mathrm{As}_{2} \mathrm{Se}_{3}$ при концентрации железа $\leq 2$ ат\% в области температур $T=80-400 \mathrm{~K}$ представляют собой квадрупольные дублеты (рис. 2), 


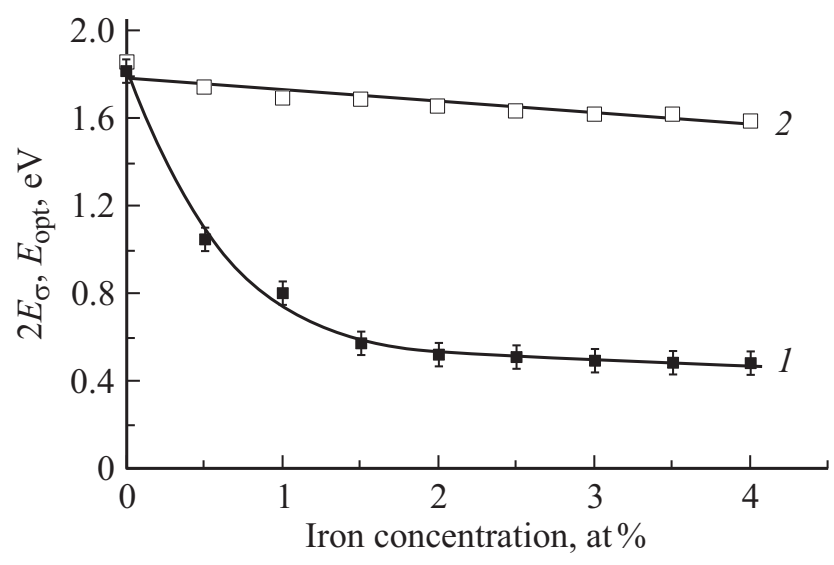

Рис. 1. Зависимости энергии активации электропроводности $E_{\sigma}(1)$ и оптической ширины запрещенной зоны $E_{\text {орt }}(2)$ от концентрации железа в пленках селенида мышьяка, модифицированного железом.

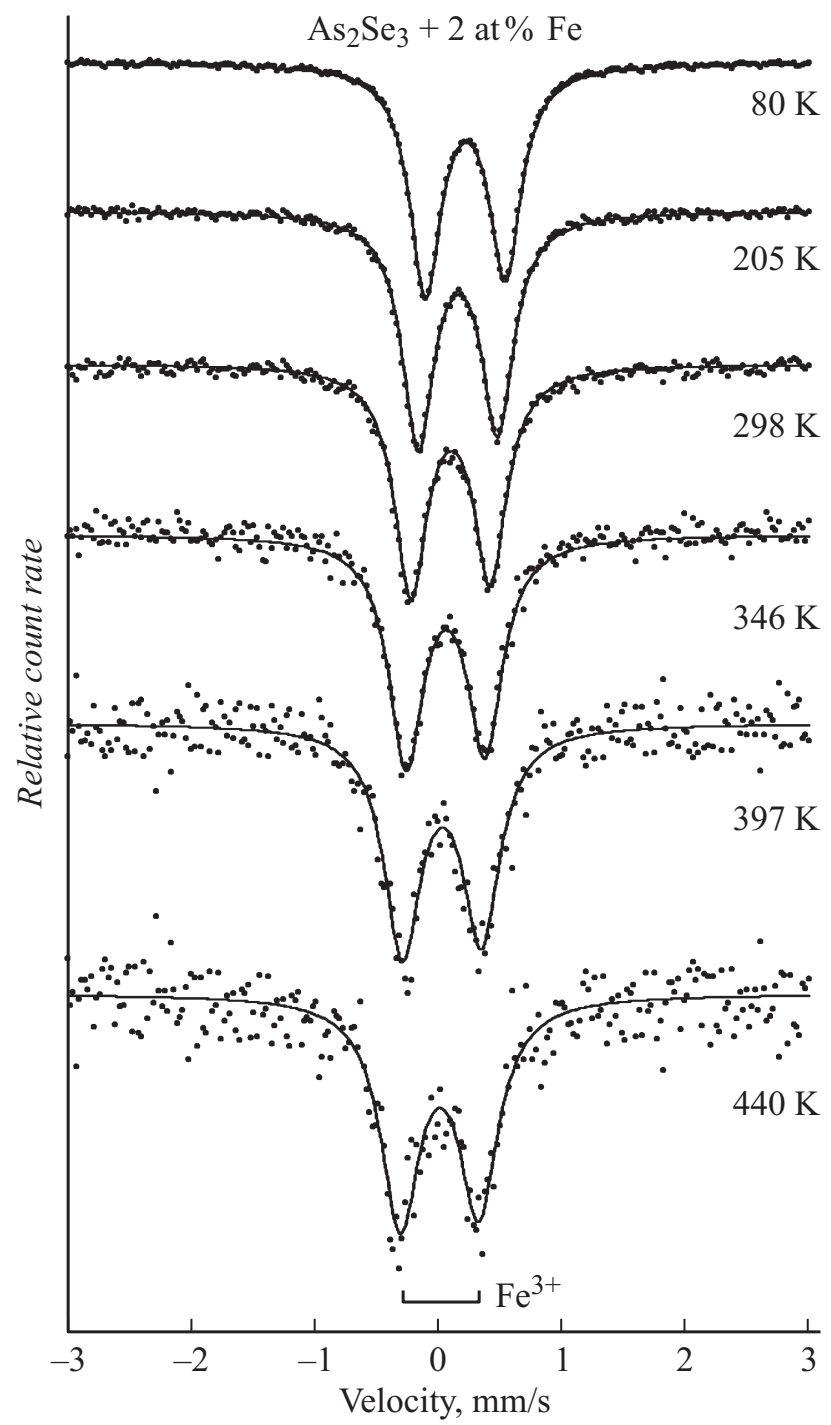

Рис. 2. Мессбауэровские спектры ${ }^{57} \mathrm{Fe}$ пленок $\mathrm{As}_{2} \mathrm{Se}_{3}+$ $+2 \mathrm{aT} \% \mathrm{Fe}$. центральный сдвиг $\left(S_{i}\right)$ и квадрупольное расщепление $\left(\Delta_{i}\right)$ которых соответствуют примесным атомам трехвалентного железа $\mathrm{Fe}^{3+}$ с симметрией локального окружения ниже кубической.

При $N_{\mathrm{Fe}}>2$ ат\% мессбауэровские спектры в области температур $T<297 \mathrm{~K}$ представляют собой суперпозицию дублета, относящегося к состоянию $\mathrm{Fe}^{3+}$, и дублета, центральный сдвиг $S_{n}$ и квадрупольное расщепление $\Delta_{n}$ которого отвечают примесным атомам двухвалентного железа $\mathrm{Fe}^{2+}$, симметрия локального окружения которого ниже кубической (рис. 3). Доля атомов $\mathrm{Fe}^{2+}$ может быть рассчитана по соотношению

$$
p=\frac{s_{n}^{80}}{s_{n}^{80}+s_{i}^{80}},
$$

где $s_{n}^{80}$ и $s_{i}^{80}$ - площади под мессбауэровскими спектрами, измеренными при температур $80 \mathrm{~K}$ и отвечающими центрам $\mathrm{Fe}^{2+}$ и $\mathrm{Fe}^{3+}$ соответственно.

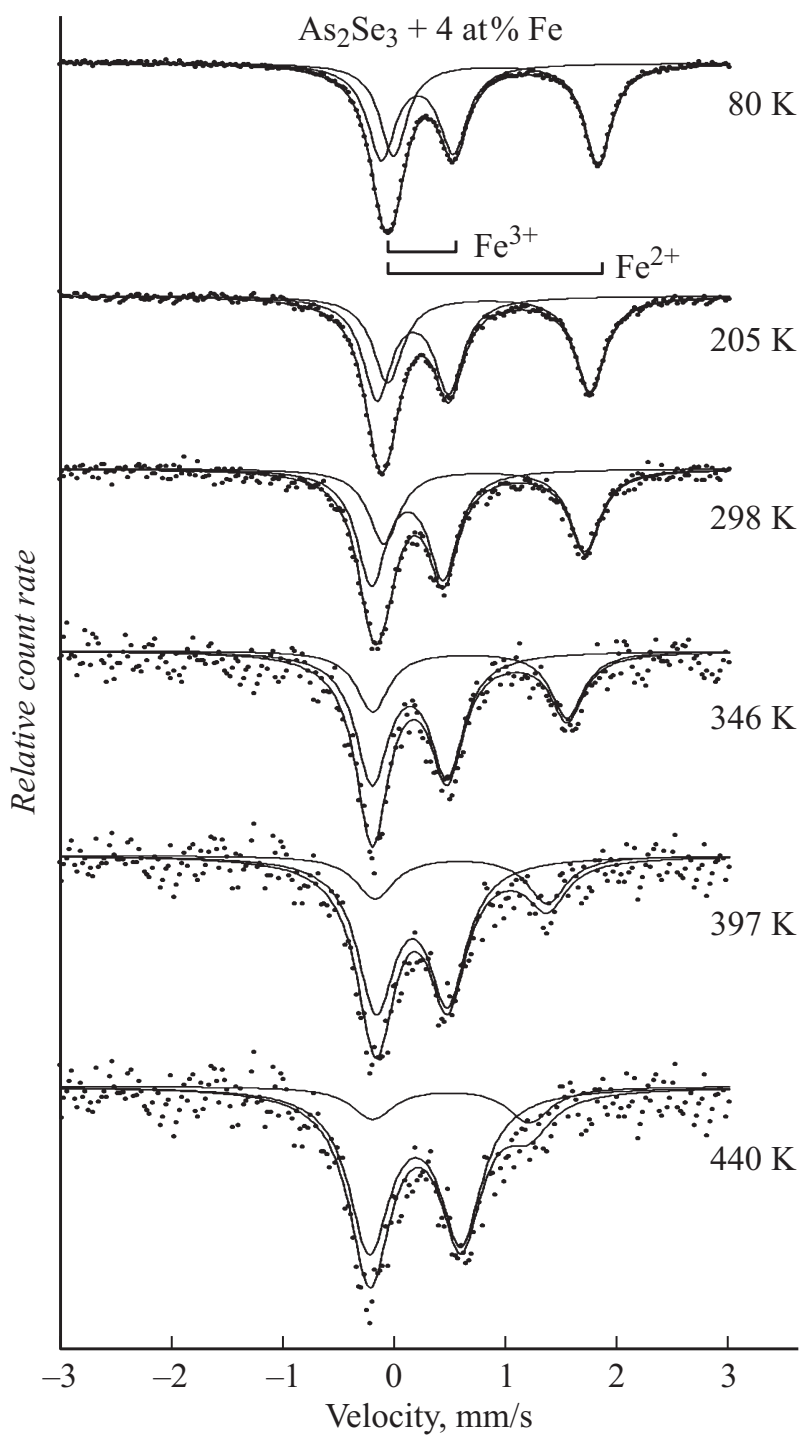

Рис. 3. Мессбауэровские спектры ${ }^{57} \mathrm{Fe}$ пленок $\mathrm{As}_{2} \mathrm{Se}_{3}+$ +4 aт\% Fe. 


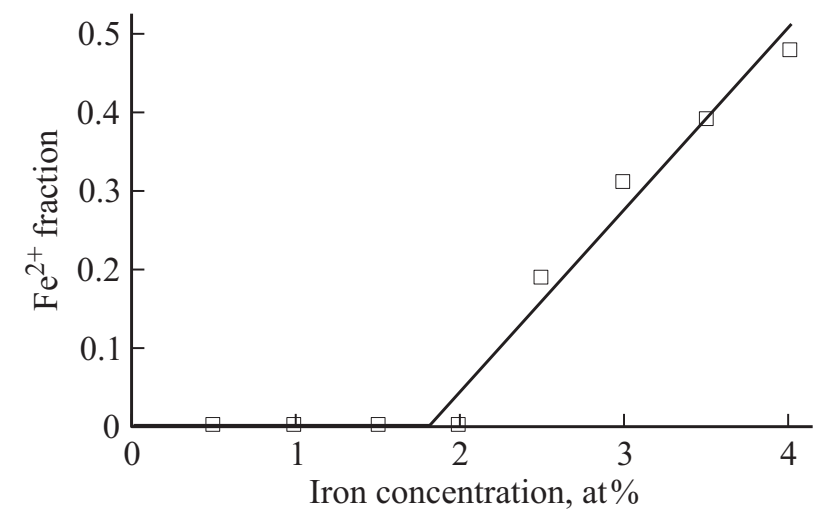

Рис. 4. Зависимость доли $\mathrm{Fe}^{2+}$ в мессбауэровских спектрах $\mathrm{As}_{2} \mathrm{Se}_{3}:{ }^{57} \mathrm{Fe}$ от концентрации железа.

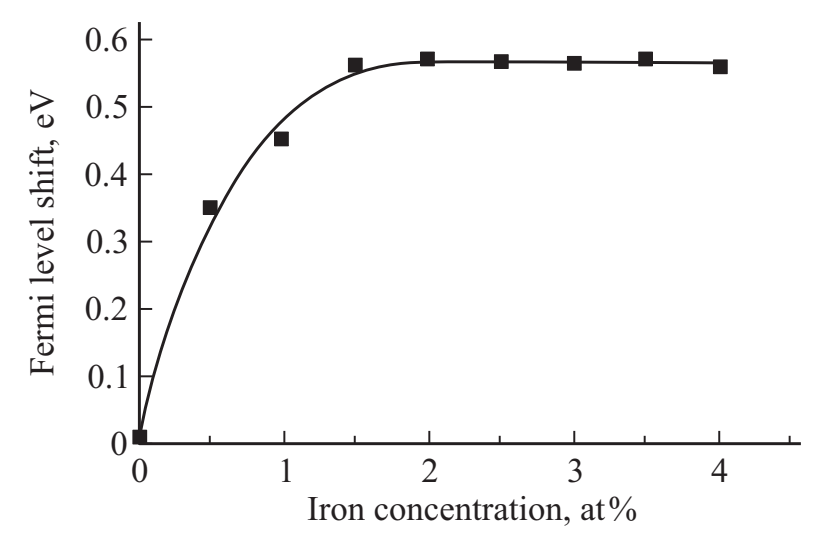

Рис. 5. Зависимость сдвига уровня Ферми от середины запрещенной зоны от концентрации железа.

Как видно из рис. 4 , доля центров $\mathrm{Fe}^{2+}$ линейно растет с ростом концентрации железа в области $N_{\mathrm{Fe}}>2$ ат\%.

Таким образом, введение железа в стеклообразный селенид мышьяка приводит к смещению уровня Ферми от середины запрещенной зоны к дну зоны проводимости: для нелегированного стекла $E_{\text {орt }} \approx 2 E_{\sigma}$ и перенос тока осуществляют дырки, тогда как введение железа в стекло приводит к смене знака носителей заряда и к уменьшению энергии активации электропроводности. На рис. 5 представлена зависимость от концентрации железа величины смещения уровня Ферми от середины запрещенной зоны $\delta E_{\mathrm{F}}=E_{\text {opt }} / 2-E_{\sigma}$, и видно, что с увеличением концентрации железа уровень Ферми плавно приближается к предельному значению, отстоящему от середины запрещенной зоны на величину $(0.57 \pm 0.03)$ эВ.

Очевидно, что примесные атомы железа образуют в запрещенной зоне стекла одноэлектронный уровень донорного типа с энергией ионизации $(0.24 \pm 0.03)$ эВ (энергия отсчитывается от дна зоны проводимости). Если $N_{\mathrm{Fe}} \leq 2$ ат\%, в области низких температур $(T<297 \mathrm{~K})$ все донорные центры железа оказываются ионизованными и в мессбауэровских спектрах примесных атомов ${ }^{57} \mathrm{Fe}$ (параметры $S_{i}$ и $\Delta_{i}$ ) наблюдается только трехвалентное железо (см. рис. 4), причем электроны донорных центров железа идут на заполнение локальных состояний, образующихся ниже уровня Ферми по механизму самокомпенсации. Именно это и приводит к смещению уровня Ферми от середины запрещенной зоны к дну зоны проводимости, причем это смещение тем больше, чем выше концентрация железа (см. рис. 5).

Когда уровень Ферми оказывается вблизи донорного уровня железа (это происходит при $N_{\mathrm{Fe}} \approx 2 \mathrm{aT} \%$ ), часть центров железа оказывается в неионизованном состоянии и в мессбауэровских спектрах примесных атомов ${ }^{57} \mathrm{Fe}$ появляется компонента, отвечающая $\mathrm{Fe}^{2+}$ (параметры $S_{n}$ и $\Delta_{n}$ ). Доля двухвалентного железа при $N_{\mathrm{Fe}}>2$ ат\% будет возрастать с ростом концентрации железа, что и наблюдается в мессбауэровских спектрах (рис. 4). Максимальное смещение уровня Ферми $(\sim 0.57$ эВ $)$ есть энергетическое положение донорного уровня железа относительно середины запрещенной зоны. Монотонное уменьшение энергии активации проводимости модифицированных железом пленок $\mathrm{As}_{2} \mathrm{Se}_{3}$ при возрастании концентрации железа объясняется описанным выше смещением уровня Ферми.

Нахождение уровня Ферми вблизи уровня железа открывает возможность электронного обмена между двумя валентными состояниями железа $\mathrm{Fe}^{2+}$ и $\mathrm{Fe}^{3+}$, что должно приводить к сближению величин центральных сдвигов спектров $\mathrm{Fe}^{2+}$ и $\mathrm{Fe}^{3+}$. В пределе быстрого электронного обмена, когда время жизни состояний $\mathrm{Fe}^{2+}$ и $\mathrm{Fe}^{3+}$ будет значительно меньше времени жизни ядерного изомера ${ }^{57 m} \mathrm{Fe}\left(\sim 10^{-7} \mathrm{c}\right)$, должен появиться мессбауэровский спектр „усредненного“ состояния железа с центральным сдвигом

$$
S=\frac{S_{i}^{80}+P S_{n}^{80}}{P+1},
$$

где

$$
P=\frac{N_{\mathrm{Fe}^{2+}}}{N_{\mathrm{Fe}^{3+}}} \leq 1
$$

Здесь $N_{\mathrm{Fe}^{2+}}$ и $N_{\mathrm{Fe}^{3+}}$ - концентрации центров $\mathrm{Fe}^{2+}$ и $\mathrm{Fe}^{3+}$ в пленках селенида мышьяка (при $80 \mathrm{~K}$ величина $P$ может быть определена из соотношения площадей под мессбауэровскими спектрами, отвечающих центрам $\mathrm{Fe}^{2+}$ и $\left.\mathrm{Fe}^{3+}\right), S_{n}^{80}$ и $S_{i}^{80}$ - центральные сдвиги мессбауэровских спектров, измеренных при температуре $80 \mathrm{~K}$, отвечающих центрам $\mathrm{Fe}^{2+}$ и $\mathrm{Fe}^{3+}$ соответственно.

На рис. 6 представлены температурные зависимости центральных сдвигов $S$ мессбауэровских спектров $\mathrm{Fe}^{3+}$ и $\mathrm{Fe}^{2+}$ для случаев $N_{\mathrm{Fe}}=2 \mathrm{aT} \%$ (когда $P \approx 0$ ) и $4 \mathrm{aT} \%$ (когда $P \approx 1$ ).

Для случая $P \approx 0$ в мессбауэровском спектре присутствует только квадрупольный дублет, отвечающий $\mathrm{Fe}^{3+}$, центральный сдвиг которого в интервале температур $T=80-440$ К лишь незначительно уменьшается с ростом температуры, что можно объяснить проявлением поперечного эффекта Допплера.

Для случая $P \approx 1$ в мессбауэровском спектре присутствуют два квадрупольных дублета, отвечающих центрам $\mathrm{Fe}^{3+}$ и $\mathrm{Fe}^{2+}$, центральные сдвиги которых с повышением температуры сближаются. Спектры на рис. 2 


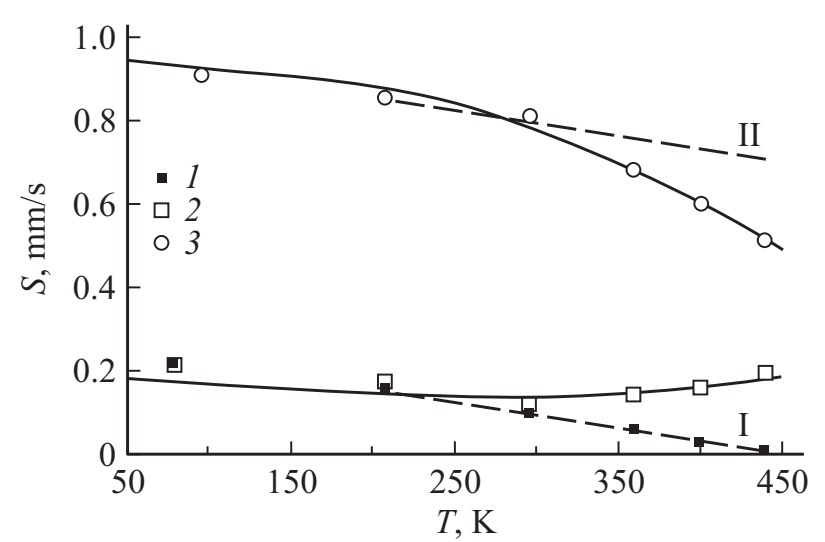

Рис. 6. Температурные зависимости центральных сдвигов $S$ мессбауэровских спектров центров $\mathrm{Fe}^{3+}$ в пленках $\mathrm{As}_{2} \mathrm{Se}_{3}$ для концентрации железа 2 (1), 4 ат\% (2) и центров $\mathrm{Fe}^{2+}$ для концентрации железа 4 ат\% (3). Штриховая линия - температурные зависимости центральных сдвигов мессбауэровских спектров центров $\mathrm{Fe}^{3+}$ (I) и центров $\mathrm{Fe} 2+(\mathrm{II})$, определяемые согласно температурной зависимости квадратичного доплеровского сдвига для мессбауэровских спектров ${ }^{57} \mathrm{Fe}$.

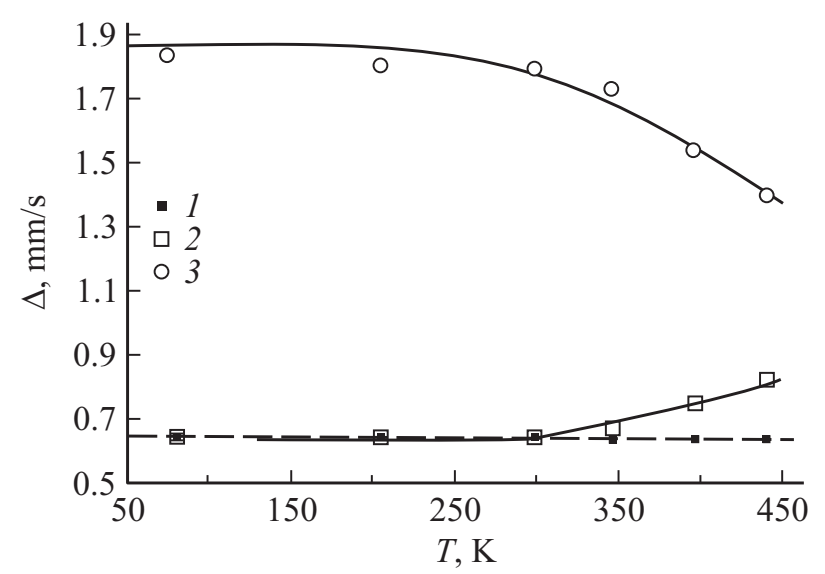

Рис. 7. Температурные зависимости квадрупольного расщепления мессбауэровских спектров центров $\mathrm{Fe}^{3+}$ в пленках $\mathrm{As}_{2} \mathrm{Se}_{3}$ для концентрации железа 2 (1), 4 ат\% (2) и центров $\mathrm{Fe}^{2+}$ для концентрации железа 4 ат\% (3).

и результаты их обработки на рис. 6 иллюстрируют типичную картину электронного обмена между двумя валентными состояниями железа $\mathrm{Fe}^{2+}$ и $\mathrm{Fe}^{3+}$.

Учитывая, что локальная симметрия центров $\mathrm{Fe}^{2+}$ и $\mathrm{Fe}^{3+}$ ниже кубической, следует ожидать наличия электронного обмена, сопровождаемого изменением тензора градиента электрического поля (ГЭП), т.е. с ростом температуры должны изменяться квадрупольные расщепления мессбауэровских спектров $\mathrm{Fe}^{2+}$ и $\mathrm{Fe}^{3+}$.

Действительно, если локальная симметрия мессбауэровского зонда ${ }^{57 m} \mathrm{Fe}$ ниже кубической, то в результате взаимодействия квадрупольного момента ядра железа $(Q)$ с тензором ГЭП на ядре энергетический уровень ядра ${ }^{57 m} \mathrm{Fe}$ расщепляется на два подуровня и возникает квадрупольное расщепление мессбауэровского спектра, который в результате представляет собой дублет с расстояниями между компонентами

$$
\Delta=\frac{1}{2} e Q U_{z z}\left[1+\frac{\eta^{2}}{3}\right]^{1 / 2},
$$

где $\eta=\left(U_{x x}-U_{y y}\right) / U_{z z}-$ параметр асимметрии тензора ГЭП, $U_{y y}, U_{x x}, U_{z z}$ - компоненты тензора ГЭП, для которых справедливо неравенство $\left|U_{x x}\right| \leq\left|U_{y y}\right| \leq\left|U_{z z}\right|$.

В общем случае имеются два источника ГЭП на ядрах атомов: ионы структурной сетки стекла (они создают „кристаллический“ ГЭП) и несферические валентные электроны мессбауэровского атома (они создают „валентный“ ГЭП). Если валентные оболочки мессбауэровского атома полностью (или наполовину) заполнены (типичный пример $\mathrm{Fe}^{3+}$ ), то для такого атома при расчетах ГЭП следует учитывать только заряды соседних атомов, величина $\Delta$ оказывается незначительной, а ее температурная зависимость определяется температурными зависимостями межатомных расстояний кристалла или структурной сетки стекла и, как правило, является очень слабой. Если же валентные оболочки мессбауэровского атома заполнены лишь частично (типичный пример $\mathrm{Fe}^{2+}$ ), основным источником ГЭП являются валентные электроны, величина $\Delta$ существенно возрастет, а с ростом температуры она заметно уменьшается [5].

На рис. 7 представлены температурные зависимости квадрупольных расщеплений мессбауэровских спектров ${ }^{57} \mathrm{Fe}$, отвечающих центрам $\mathrm{Fe}^{2+}$ и $\mathrm{Fe}^{3+}$. Видно, что в интервале температур 80-400 К для случая концентрации железа в пленках < 2 ат\% (железо стабилизируется только в состоянии $\mathrm{Fe}^{3+}$ ) наблюдаются малая величина квадрупольного расщепления $\Delta$ и ее незначительное уменьшение с ростом температуры, что и следовало ожидать для трехвалентного состояния железа. Для случая концентрации железа 4 ат\% (железо стабилизируется в двух равнозаселенных состояниях $\mathrm{Fe}^{3+}$ и $\mathrm{Fe}^{2+}$ ) в интервале температур 80-350 K для спектров $\mathrm{Fe}^{3+}$ наблюдаются малые величины $\Delta$ и их уменьшение с ростом температуры, тогда как при дальнейшем возрастании температуры величина $\Delta$ начинает аномально увеличиваться. Для этих же образцов в спектрах $\mathrm{Fe}^{2+}$ величина квадрупольного расщепления $\Delta$ существенно выше и скорость ее уменьшения с ростом температуры имеет две области: при температурах 80-350 К квадрупольное расщепление заметно уменьшается, и при $T>350 \mathrm{~K}$ это уменьшение становится более резким.

Таким образом, с ростом температуры наблюдается сближение величин квадрупольного расщепления мессбауэровских спектров $\mathrm{Fe}^{3+}$ и $\mathrm{Fe}^{2+}$ в пленках стеклообразного селенида мышьяка, что свидетельствует о сближении параметров тензора ГЭП на ядрах атомов нейтральных и ионизованных донорных центров железа.

\section{4. Заключение}

В стеклообразных пленках селенида мышьяка, модифицированного железом, обнаружены центры $\mathrm{Fe}^{2+}$ и 
$\mathrm{Fe}^{3+}$, которые соответствуют нейтральному и ионизованному состояниям донорного одноэлектронного центра железа. Соотношение концентраций центров $\mathrm{Fe}^{2+}$ и $\mathrm{Fe}^{3+}$ зависит от состава стекла (доля центров растет с ростом содержания железа в стеклах), причем уровень Ферми с ростом концентрации железа сдвигается к дну зоны проводимости (с увеличением концентрации железа ширина запрещенной зоны стеклообразного селенида мышьяка, определенная по температурной зависимости электропроводности, уменьшается, тогда как оптическая ширина запрещенной зоны практически не изменяется). C ростом температуры наблюдается сближение как величин центрального сдвига мессбауэровских спектров $\mathrm{Fe}^{3+}$ и $\mathrm{Fe}^{2+}$, так и величин квадрупольного расщепления этих спектров, что свидетельствует о выравнивании и электронной плотности, и параметров тензора ГЭП на ядрах атомов нейтральных и ионизованных донорных центров железа.

\section{Список литературы}

[1] Г.А. Бордовский, С.А. Немов, А.В. Марченко, П.П. Серегин. ФТП, 46, 3 (2012).

[2] Ф.С. Насрединов, С.А. Немов, В.Ф. Мастеров, П.П. Серегин. ФТП, 30, 840 (1996).

[3] А.В. Марченко, Д.В. Жилина, К.У. Бобохужаев, А.В. Николаева, Е.И. Теруков, П.П. Серегин. ФТТ, 57, 1928 (2015).

[4] Г.А. Бордовский, А.В. Марченко, П.П. Серегин, Н.Н. Смирнова, Е.И. Теруков. ФТП, 44, 26 (2010).

[5] Г.А. Бордовский, А.В. Марченко. Идентификация $U$-центров в кристаллических и стеклообразных полупроводниках и полуметаллах методом мессбауэровской спектроскопии (СПб., Наука, 2010).

Редактор Л.В. Шаронова

\section{Electronic exchange between neutral and ionized impurity iron centers in glassy arsenic selenide}

\author{
A.V. Marchenko ${ }^{1}$, E.I. Terukov ${ }^{2}$, A.Yu. Egorova ${ }^{3}$, \\ V.S. Kiselev ${ }^{1}$, P.P. Seregin ${ }^{1}$ \\ ${ }^{1}$ Herzen State Pedagogical University of Russia, \\ 191186 St. Petesburg, Russia \\ ${ }^{2}$ Ioffe Institute, \\ 194021 St. Petersburg, Russia \\ ${ }^{3}$ Saint-Petersburg Mining University, \\ 199106 St. Petersburg Russia
}

\begin{abstract}
The impurity iron atoms in arsenic selenide $\mathrm{As}_{2} \mathrm{Se}_{3}$ glassy films, modified with iron, form one-electron donor centers with the ionization energy $0.24(3) \mathrm{eV}$ (the energy is measured from the bottom of the coduction band). When the iron concentration increases then the Fermi level shifts from the middle of the gap to the position of the iron donor level due to filling of single-electron acceptor states below the Fermi level. When the iron concentration is $\geq 3$ at $\%$ and the temperature is increased above $350 \mathrm{~K}$, then the electron exchange is observed between the neutral and ionized iron centers, leading to a change in the electron density and the tensor of the electric gradient field at the nuclei of iron atoms.
\end{abstract}

